\title{
SUBPROVÍNCIAS HIDROGEOLÓGICAS DO GRUPO BAURU NA REGIÃO NORTE-OCIDENTAL DO ESTADO DE SÃO PAULO
}

\author{
SAMIR FELÍCIO BARCHA * \\ FAHAD MOYSÉS ARID * \\ SÉRGIO MEZZALIRA **
}

\section{RESUMO}

Face à crescente demanda de água para fins industrial, agrícola e urbano, estão sendo construídos numerosos poços profundos na região norte-ocidental do Estado de São Paulo, visando a captação de água subterrânea contida nos aquíferos dos sedimentos do Grupo Bauru. Estes poços têm revelado substanciais diferenças em suas vazões, consequência não apenas de suas características técnicas de construção, mas especialmente devidas a fatores geológicos.

Os dados obtidos permitiram estabelecer, como causas fundamentais desta variação, a porosidade e a permeabilidade, as quais variam em função da textura, do teor e do comportamento do cimento carbonático.

Verificou-se também que a variação na produtividade tem significação regional, isto é, apresenta valores diversos em diferentes áreas.

Baseados neste fato, os autores puderam estabelecer a existência de, pelo menos, três subprovíncias hidrogeológicas na região estudada, delimitando, ainda que de forma preliminar, áreas mais e menos promissoras para a exploração de água subterrânea.

The growing exploration of de subterranean water resources of the northwestern region of the State of São Paulo has revealed great variations in the productivity of open wells in the Bauru aquifer.

Proceeding from a detailed study of the lithology, sedimentary structures and stratigraphic behavior of the Bauru Group which covers the region studied, it was verified that this variation is determined rather by the geological characteristics of the Bauru sediments than by the different technical patterns of the wells bored in it.

The data obtained establishes, as fundamental causes of this variation, porosity and permeability which vary in function, of the texture, content and behavior of the carbonate ciment of the rocks.

It was also verified that the variation in productivity of the Bauru aquifer has regional significance, that is, it represents diverse values in different areas.

Based in this fact, the authors were able to establish the existence of at least three hydrogeological provinces in the region studied, delimiting, although only provisionally, areas more and less promising for the exploration of subterranean water.

\section{INTRODUÇÃO}

Durante os últimos anos, a intensificação dos estudos hidrogeológicos na região norteocidental do Estado, bem como o número elevado de perfurações para captação de água subterrânea, tem chamado a atenção dos autores para a grande variação na produtividade dos poços abertos no Aquífero Bauru.

Procuraram, então, em suas observações, verificar as prováveis causas dessa variabilidade da produção dos poços, a qual ocorria até em poços próximos um do outro.

A própria gênese do Grupo Bauru, continental, com variações litológicas laterais e verticais, constituia uma das principais causas dessa irregularidade de produção, dificultando uma generalização para todo o Grupo, que cobre uma área de $104.000 \mathrm{Km}^{2}$ do Estado de São Paulo.

Após exame da litologia, comportamento espacial, estruturas sedimentares, cimento, posição estratigráfica do poço e o contato Bauru-Basalto existente, chegaram os autores a algumas observações e conclusões interessantes sobre o comportamento do Aquífero Bauru, principalmente na região norteocidental do Estado e que constituem os objetivos principais deste trabalho.

Naturalmente, trata-se de uma primeira

\footnotetext{
* Departamento de Geociências - Instituto de Biociências, Letras e Ciências Exatas de São José do Rio Preto - UNESP.
}

** Geólogo - Pesquisador Científico - Diretoria Geral - Instituto Geológico. 
tentativa para explicar essa variabilidade no Aquífero Bauru. Tentou-se estender essas observações para a área restante do Bauru, ocorrente no Estado, mas por falta de dados específicos de perfis geológicos, não foi possivel chegar-se a conclusões satisfatórias, muito embora existam inúmeros poços perfurados, mas sem o detalhamento necessário aos estudos.

\section{GEOLOGIA E ESTRATIGRAFIA}

A litologia e o comportamento espacial, bem como as estruturas sedimentares primárias do Grupo Bauru no Estado de São Paulo já estão bem definidas graças às contribuições de FREITAS $(1955,1964)$, ARID (1967), MEZZALIRA (1974), BARCHA \& ARID (1977), SUGUIO et alii (1977), SOARES et alii $(1979,1980)$ e BARCHA (1980).

Em superfície, o sedimento mostra variação na textura, formando corpos de pequena espessura e extensão, interdigitando-se horizontalmente. São freqüentes lentes de arenitos grosseiros a muito finos, siltitos e argilitos, bem como conglomerados de seixos de argilito. Essa variação é também observada na seqüência vertical, sendo uma constante em muitos poços analisados na área estudada. A predominância dos termos arenosos no perfil vertical, em algumas áreas, chega a ser absoluta, em outras é subordinada, fato que determina valores muito discrepantes da razão de clásticos, quando se confrontam tais áreas entre si. Essa razão de clásticos representa, como demonstrou BARCHA (1980) um dos fatores responsáveis pela alta ou baixa capacidade armazenadora e produtora de água do Grupo Bauru na região norte-ocidental do Estado de São Paulo.

A mesma repetição ocorre em relação às estruturas sedimentares primárias, as quais variam de maciça à laminação horizontal e aos tipos cruzados. Tais estruturas ocorrem ao longo de todo o perfil vertical, sendo mais abundantes, pela ordem, a estrutura maciça, laminação cruzada festonada e planar, laminação horizontal. Contudo, existem áreas dentro da região estudada, caracterizadas pela maior ou menor freqüência com que se registram essas estruturas hidrodinâmicas, a ponto de se diferenciarem muito umas das outras quando cotejadas entre si.

Quanto à estratigrafia, os autores basearam-se nos estudos de SOARES et alii (1980) e de BARCHA (1980a). Na região registra-se a ocorrência da Formação Santo Anastácio e da Formação Adamantina, apenas esta última extensivamente, uma vez que os sedimentos da primeira não são encontra- dos em muitos pontos amostrados.

A Formação Santo Anastácio caracterizase por apresentar, predominantemente, arenitos maciços, de granulação grosseira, média ou fina, pouca matriz, seleção boa a regular e cores avermelhadas e vermelhoarroxeadas. Além disso é pobre em estruturas sedimentares e quando estas ocorrem, predominam a plano-paralela e cruzada planar. Em corpos com estas estruturas ocorrem, associadamente, arenitos muito finos, lamíticos, bem como lentes descontínuas de siltitos e argilitos de cores marron, vermelho, e lentes de argilito esverdeado. Esses clásticos muito finos são conspícuos na periferia das áreas abrangidas pela Formação, enquanto que para o interior, são mais freqüentes corpos de textura mais grosseira, dominantemente arenosa.

Em superfície, a Formação Santo Anastácio ocorre ao longo da margem esquerda do Rio Paraná, sendo registrada na área de Santa Fé do Sul e daí, para o sul, passando por Palmeira D'Oeste, Guzolândia, Pereira Barreto e Sud Mennucci.

Em subsuperfície, é registrada em sondagens na margem esquerda do Rio Grande, área de Macedônia, na Bacia do Rio Turvo (Bálsamo, São José do Rio Preto, Palestina) e na Bacia do Rio São José dos Dourados (Auriflama e Magda). Sondagens realizadas em Tanabi, Ecatu, Simonsen, Cosmorama e Votuporanga não registraram a presença desses sedimentos, fato explicado, segundo BARCHA (1980 a), pela existência de um alto estrutural do substrato basáltico na área. Da mesma forma, sua presença também não foi registrada em sondagens efetuadas nas imediações de Penápolis, Avanhadava, Planalto e na cidade de Lins.

Recobrindo a Formação Santo Anastácio ou assentando-se diretamente no basalto, encontra-se a Formação Adamantina, de fato, a litologia mais expressiva que recobre a maior superfície da região estudada. Estende-se por toda a Bacia do Rio Turvo, e constitui os espigões em ambas as margens do Alto e Médio São José dos Dourados, continuando-se ainda para o Sul, até o divisor do Baixo Tietê (porção inicial) e do Rio Aguapeí.

A Formação Adamantina caracteriza-se pela presença de arenitos de granulação média a muito fina, por siltitos e argilitos na forma de finas lentes ou de espessos bancos com vários metros de espessura, variação esta que se repete muitas vezes na seqüência vertical. As cores são ou do grupo do vermelho, com tonalidade rósea, castanho, creme, 
ou do grupo do cinza, com tonalidades cinza-creme, cinza-esverdeada ou esverdeada. Estruturas hidrodinâmicas são muito freqüentes, destacando a laminação planoparalela e os tipos cruzados.

As variações regionais levaram SOARES et alii (1980) a uma divisão da Formação, sendo propostas, para a região em estudo no presente trabalho, as Fácies São José do Rio Preto e Taciba.

A Fácies São José do Rio Preto é constituída por arenitos ricos em estruturas sedimentares, representando uma fácies de canal. A Fácies Taciba, caracterizada por um interacamamento de siltitos, argilitos e arenitos muito finos, com predominância de clásticos finos na coluna, representa uma fácies de planície de inundação.

A Fácies São José do Rio Preto ocorre em toda a Bacia do Rio Turvo, inclusive na área do alto estrutural Tanabi-Votuporanga, estendendo-se até às proximidades de Jales. Daí para Oeste, é substituída pela Faćies Taciba a qual recobre também toda a margem esquerda do Alto e Médio São José dos Dourados, bem como as áreas de Penápolis, Ara- çatuba, Avanhandava, Lins, Planalto e Monte Aprazível.

\section{PROPRIEDADES HIDROGEOLÓGICAS DOS SEDIMENTOS}

As propriedades hidrogeológicas dos sedimentos do Grupo Bauru foram estudadas em amostras de sondagens para captação de água subterrânea, desde os níveis mais superfíciais até o contacto com o basalto sobjacente. Os ensaios foram efetuados em amostras provenientes de poços perfurados nas localidades de São José do Rio Preto (E.T.A.; Maria Benta - Centro Social; Chácara Giglio), Tanabi, Destilaria Água Limpa (Monte Aprazível), Fazenda Luchesi (Planalto), Usina Campestre (Penápolis), Auriflama (Rod. Auriflama - Jales, a 10 $\mathrm{km}$. da saída de Auriflama), Fazenda Beolchi e Fazenda Santa Rosa, ambas em Sud Mennucci.

Em laboratório, foram determinados em cada poço, a razão de clásticos, o teor de carbonato na forma de cimento, a textura, a porosidade e a permeabilidade (Tab. 1).

TABELA 1

Tab.1a - Propriedades texturais e hidrogeológicas de sedimentos de sondagens no Grupo Bauru.

LOCAL: PREFEITURA - E.T.A.

\begin{tabular}{|c|c|c|c|c|c|c|c|}
\hline $\begin{array}{c}\text { AMOSTRA } \\
\text { (Prof.) } \\
\text { m }\end{array}$ & $\begin{array}{c}\text { AREIA } \\
\%\end{array}$ & $\begin{array}{c}\text { SILTE + } \\
\text { ARGILA\% }\end{array}$ & $\begin{array}{c}\mathrm{CaC} 03 \\
\%\end{array}$ & $\begin{array}{c}\text { POROSID } \\
\%\end{array}$ & $=$ & $\begin{array}{l}\text { PERN } \\
\perp\end{array}$ & $\begin{array}{l}\text { LIDADE } \\
\text { S.O. }\end{array}$ \\
\hline $\begin{array}{l}13 \\
16 \\
17 \\
18 \\
20 \\
22 \\
23 \\
24 \\
26,5 \\
29 \\
35 \\
36 \\
45 \\
46 \\
48 \\
50 \\
51 \\
56 \\
68 \\
77 \\
78 \\
80 \\
84 \\
86 \\
88 \\
90 \\
92 \\
93 \\
94 \\
105 \\
115 \\
117\end{array}$ & $\begin{array}{r}90,89 \\
90,81 \\
76,64 \\
86,09 \\
79,77 \\
87,17 \\
85,34 \\
98,12 \\
91,38 \\
95,78 \\
90,58 \\
96,18 \\
87,73 \\
96,94 \\
90,50 \\
- \\
84,33 \\
78,63 \\
92,11 \\
90,84 \\
91,75 \\
93,64 \\
91,84 \\
92,89 \\
92,46 \\
93,07 \\
96,02 \\
89,44 \\
90,59 \\
88,64 \\
77,72 \\
97,76\end{array}$ & $\begin{array}{r}9,11 \\
9,19 \\
24,36 \\
13,91 \\
20,23 \\
12,83 \\
14,66 \\
1,88 \\
8,62 \\
4,22 \\
9,42 \\
3,82 \\
12,27 \\
3,06 \\
9,5 \\
- \\
15,67 \\
21,32 \\
7,89 \\
9,16 \\
8,25 \\
6,36 \\
8,16 \\
7,11 \\
7,54 \\
6,93 \\
3,98 \\
10,56 \\
9,41 \\
11,36 \\
22,28 \\
2,24\end{array}$ & $\begin{array}{r}1,8 \\
8,2 \\
1,5 \\
4,6 \\
10,0 \\
10,0 \\
4,5 \\
2,8 \\
5,3 \\
27,7 \\
8,5 \\
\\
3,90 \\
6,4 \\
2,9 \\
\\
5,2 \\
\\
2,2 \\
6,3 \\
2,2 \\
7,9 \\
1,7 \\
3,9 \\
1,8 \\
2,9 \\
3,1 \\
3,2 \\
2,70 \\
34,7 \\
24,3\end{array}$ & $\begin{array}{r}22,98 \\
7,13 \\
24,85 \\
19,77 \\
4,08 \\
12,97 \\
10,14 \\
30,03 \\
26,71 \\
11,87 \\
21,98 \\
11,05 \\
28,90 \\
8,14 \\
\\
12,81 \\
\\
\\
18,80 \\
17,99 \\
21,22 \\
22,22 \\
23,90 \\
13,75 \\
22,77 \\
13,93 \\
23,19 \\
24,15 \\
26,92 \\
\\
13,29\end{array}$ & $\begin{array}{c}44,3 \\
- \\
\overline{-} \\
0,0 \\
\overline{165} \\
763,5 \\
643,3 \\
56,0 \\
516,1 \\
0,0 \\
2.572,6 \\
529 \\
0,0 \\
\\
- \\
- \\
- \\
- \\
- \\
- \\
- \\
- \\
- \\
-\end{array}$ & $\begin{array}{c}33,8 \\
- \\
- \\
\overline{0}, 0 \\
- \\
20 \\
628,1 \\
95,3 \\
8 \\
516,1 \\
0,0 \\
857,8 \\
79 \\
0,0 \\
\\
- \\
- \\
- \\
- \\
- \\
- \\
- \\
- \\
- \\
-\end{array}$ & $\begin{array}{c}\overline{0}, 0 \\
516,1 \\
0,0 \\
\overline{-} \\
109,2 \\
- \\
- \\
- \\
- \\
- \\
- \\
- \\
- \\
\\
- \\
\\
82,4 \\
105,4 \\
160,1 \\
73,5 \\
286,0 \\
156,0 \\
362,2 \\
572,0 \\
183,4 \\
159,7 \\
220 \\
14,1\end{array}$ \\
\hline
\end{tabular}

$=$ paralelo à estrutura

S.O. sem orientação

1 perpendicular à estrutura

K (m.D.) - Permeabilidade em milidarcies 
Tab. $1 \mathrm{~b}-$ Cont.

LOCAL: CHÁCARA GIGLIO

\begin{tabular}{|c|c|c|c|c|c|c|c|}
\hline \multirow{2}{*}{$\begin{array}{l}\text { AMOSTRA } \\
\text { (Prof.) } \\
\text { m }\end{array}$} & \multirow{2}{*}{$\begin{array}{c}\text { AREIA } \\
\%\end{array}$} & \multirow{2}{*}{$\begin{array}{c}\text { SILTE + } \\
\text { ARGILA } \%\end{array}$} & \multirow{2}{*}{$\begin{array}{c}\mathrm{CaC} 03 \\
\%\end{array}$} & \multicolumn{2}{|c|}{ POROSIDADE } & \multicolumn{2}{|c|}{$\begin{array}{l}\text { PERMEA.BILIDADE } \\
\text { K(m.D.) }\end{array}$} \\
\hline & & & & $\%$ & $=$ & $\perp$ & S.O. \\
\hline 11 & 93,00 & 7,00 & 1,70 & 28,81 & $1.007,2$ & 98,5 & - \\
\hline 14,5 & 91,35 & 8,65 & 2,53 & 30,77 & 503,9 & 142,0 & - \\
\hline 17 & 83,15 & 16,85 & 3,43 & 30,00 & 35,6 & 31,4 & - \\
\hline 19 & 93,70 & 6,30 & 3,85 & 28,50 & - & - & 100,5 \\
\hline 22 & 84,35 & 15,63 & 7,23 & 25,50 & - & - & 31,9 \\
\hline 24 & 94,95 & 5,05 & 3,19 & 23,72 & 23,2 & 17,1 & - \\
\hline 26 & 94,80 & 5,20 & 3,57 & 25,20 & - & - & 104,6 \\
\hline 28 & 93,80 & 6,60 & 3,35 & 24,96 & - & - & 23,4 \\
\hline 29,5 & 94,35 & 5,65 & 2,24 & & & & \\
\hline 31,5 & 95,95 & 4,05 & 3,27 & 28,94 & 48,3 & 35,8 & - \\
\hline 32,5 & 94,20 & 5,80 & 22,23 & 13,46 & & & \\
\hline 35 & 93,95 & 6,05 & 6,37 & 17,94 & 319,01 & 143,5 & - \\
\hline 37 & 93,30 & 6,70 & 5,27 & 23,12 & 119,6 & 58,4 & - \\
\hline 40 & 92,70 & 7,30 & 4,16 & 20,91 & - & - & 27,9 \\
\hline 43 & 96,35 & 3,65 & 3,18 & 29,90 & 717,8 & 295,6 & - \\
\hline 46 & 95,95 & 4,05 & 6,28 & 23,62 & 314,0 & 209,3 & - \\
\hline 50 & 95,90 & 4,10 & 3,40 & 31,64 & 157,0 & 125,5 & - \\
\hline 54 & 96,35 & 3,65 & 1,95 & 36,60 & $1.256,3$ & 570,0 & - \\
\hline 58 & 93,65 & 6,35 & 5,04 & 25,35 & 125,6 & 39,8 & - \\
\hline 62 & 88,90 & 11,10 & 5,12 & 28,10 & 179,6 & 25,6 & - \\
\hline 65 & 80,55 & 19,45 & 9,98 & 15,94 & - & - & 14,9 \\
\hline $67-80$ & $\pm 95,00$ & $\pm 5,00$ & 2,86 & 22,00 & - & - & 350,0 \\
\hline $87-101$ & $\pm 95,00$ & $\pm 5,00$ & 2,28 & 22,00 & - & - & 360,0 \\
\hline
\end{tabular}

Tab. 1c - Cont.

LOCAL: FAZENDA BEOLCHI (SUD MENNUCCI)

\begin{tabular}{|c|c|c|c|c|c|c|c|}
\hline \multirow{2}{*}{$\begin{array}{l}\text { AMOSTRA } \\
\text { (Prof.) } \\
\mathrm{m}\end{array}$} & \multirow{2}{*}{$\begin{array}{c}\text { AREIA } \\
\% \\
\end{array}$} & \multirow{2}{*}{$\begin{array}{c}\text { SILTE + } \\
\text { ARGIL.A\% }\end{array}$} & \multirow{2}{*}{$\begin{array}{c}\mathrm{CaC} 03 \\
\%\end{array}$} & \multirow{2}{*}{$\begin{array}{c}\text { POROSIDADE } \\
\% \\
\end{array}$} & \multirow[b]{2}{*}{$=$} & \multicolumn{2}{|c|}{$\begin{array}{l}\text { PERMEABILIDADE } \\
\text { K(m.D.) }\end{array}$} \\
\hline & & & & & & \pm & S.O. \\
\hline 10 & 84,85 & 15,15 & 2,83 & 19,80 & - & - & 0,0 \\
\hline 12 & 92,00 & 8,00 & 2,42 & 24,04 & - & - & \\
\hline 15 & 86,40 & 13,60 & 10,40 & 12,75 & - & - & 0,0 \\
\hline 20 & 91,45 & 8,55 & 2,17 & 19,60 & - & - & 58,95 \\
\hline 25 & 87,20 & 12,80 & 1,72 & 22,05 & - & - & 2,00 \\
\hline 30 & 75,40 & 24,60 & 3,99 & 21,03 & - & - & 3,50 \\
\hline 32 & 87,05 & 12,95 & 2,78 & 16,40 & - & - & 0,00 \\
\hline 35 & 90,25 & 9,75 & 5,01 & 38,71 & - & - & 0,00 \\
\hline 40 & 83,55 & 16,45 & 4,36 & 13,02 & - & - & 0,00 \\
\hline 45 & 83,10 & 16,90 & 2,50 & 18,86 & -- & - & 2,10 \\
\hline 50 & $87 \$ 30$ & 12,70 & 3,25 & 17,11 & - & - & 14,73 \\
\hline 55 & 86,45 & 13,55 & 5,40 & 13,23 & - & - & 2,94 \\
\hline 60 & 92,60 & 7,40 & 8,42 & 19,19 & - & - & 41,20 \\
\hline 70 & 91,75 & 8,25 & 2,32 & 24,24 & - & - & 186,69 \\
\hline 75 & 86,20 & 13,80 & 2,13 & 16,94 & - & - & 0,00 \\
\hline 82 & 90.20 & 9,80 & 1,23 & 20,78 & - & - & 56,00 \\
\hline 84 & 88,10 & 11,90 & 4,39 & 14,70 & - & - & - \\
\hline
\end{tabular}


Rev. IG, São Paulo, 2(2):17-33, jun./dez. 1981

Tab. Id - Cont.

LOCAL: Destilaria Água Limpa - Monte Aprazivel

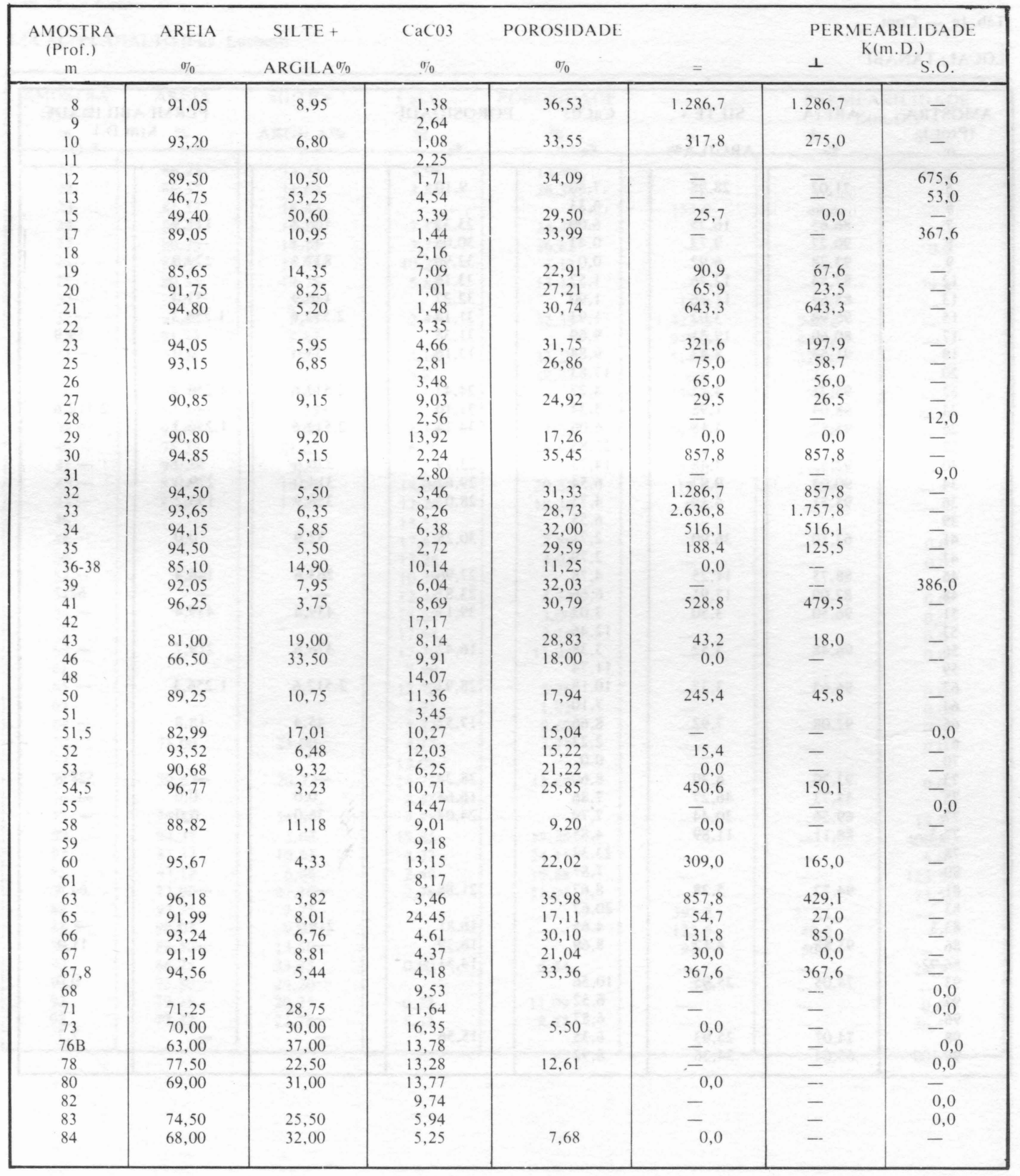


Tab. le - Cont.

LOCAL: TANABI

\begin{tabular}{|c|c|c|c|c|c|c|c|}
\hline $\begin{array}{l}\text { AMOSTRA } \\
\text { (Prof.) } \\
\text { m }\end{array}$ & $\begin{array}{l}\text { AREIA } \\
\%\end{array}$ & $\begin{array}{l}\text { SILTE + } \\
\text { ARGILA } \%\end{array}$ & $\begin{array}{c}\mathrm{CaC} 03 \\
\%\end{array}$ & $\begin{array}{c}\text { POROSIDADE } \\
\%\end{array}$ & $=$ & $\begin{array}{l}\text { PERI } \\
\perp\end{array}$ & $\begin{array}{l}\text { ILIDADE } \\
\text { D.) } \\
\text { S.O. }\end{array}$ \\
\hline $\begin{array}{l}5 \\
6 \\
7 \\
8 \\
9 \\
12 \\
13 \\
15 \\
17 \\
19 \\
20 \\
22 \\
24 \\
26 \\
27 \\
30 \\
34 \\
36 \\
39 \\
41 \\
43 \\
46 \\
48 \\
51 \\
53 \\
56 \\
59 \\
62 \\
64 \\
66 \\
67 \\
70 \\
73 \\
75 \\
77 \\
77,5 \\
78 \\
80 \\
81 \\
83 \\
83,5 \\
86 \\
86-92 \\
93 \\
94 \\
96 \\
98 \\
99-100\end{array}$ & $\begin{array}{l}71,02 \\
86,65 \\
90,27 \\
93,28 \\
87,54 \\
88,64 \\
96,98 \\
80,69 \\
91,57 \\
95,75 \\
98,04 \\
95,82 \\
92,52 \\
90,03 \\
95,81 \\
63,10 \\
88,75 \\
82,09 \\
96,50 \\
96,48 \\
96,63 \\
\\
92,08 \\
\\
93,70 \\
53,73 \\
69,56 \\
88,11 \\
\\
94,72 \\
\\
95,88 \\
74,05 \\
\\
74,07 \\
65,64\end{array}$ & $\begin{array}{r}28,98 \\
16,35 \\
9,73 \\
6,92 \\
12,46 \\
11,36 \\
3,02 \\
19,31 \\
8,43 \\
4,25 \\
1,96 \\
4,18 \\
7,48 \\
99,97 \\
4,19 \\
36,90 \\
11,25 \\
17,91 \\
3,50 \\
3,52 \\
3,37 \\
7,92 \\
\\
6,30 \\
46,27 \\
30,44 \\
11,89 \\
\\
5,28 \\
4,12 \\
25,95 \\
25,93 \\
34,36\end{array}$ & $\begin{array}{r}7,80 \\
6,33 \\
6,00 \\
0,43 \\
0,0 \\
1,52 \\
1,90 \\
1,93 \\
9,69 \\
9,84 \\
17,83 \\
4,27 \\
5,34 \\
6,06 \\
25,85 \\
14,73 \\
6,54 \\
4,75 \\
6,55 \\
2,71 \\
2,79 \\
4,78 \\
6,66 \\
3,02 \\
12,46 \\
3,38 \\
11,74 \\
10,18 \\
7,10 \\
8,66 \\
2,23 \\
0,0 \\
8,60 \\
7,86 \\
7,79 \\
4,85 \\
23,34 \\
7,87 \\
8,67 \\
20,62 \\
4,65 \\
8,69 \\
10,56 \\
6,52 \\
6,87 \\
6,35 \\
6,92\end{array}$ & $\begin{array}{l}9,10 \\
23,35 \\
30,08 \\
32,90 \\
33,16 \\
32,27 \\
31,14 \\
31,38 \\
13,16 \\
34,43 \\
31,10 \\
34,14 \\
23,79 \\
29,62 \\
28,07 \\
30,28 \\
\\
27,96 \\
23,87 \\
39,17 \\
16,47 \\
28,93 \\
\\
17,52\end{array}$ & $\begin{array}{r}160,8 \\
48,3 \\
837,5 \\
146,9 \\
2.512,6 \\
53,0 \\
2.512,6 \\
-512,6 \\
376,6 \\
314,0 \\
358,9 \\
32,9 \\
263,6 \\
439,4 \\
376,6 \\
2.512,6 \\
45,4 \\
\\
0,0 \\
36,0\end{array}$ & $\begin{array}{r}111,9 \\
-279,0 \\
53,0 \\
1.256,3 \\
0,0 \\
1.256,3 \\
- \\
1.256,3 \\
53,0 \\
279,0 \\
193,2 \\
0,0 \\
146,4 \\
-739,4 \\
219,7 \\
1.256,3 \\
18,8 \\
\\
0,0 \\
0,0\end{array}$ & $\begin{array}{l}- \\
\overline{5} \\
59,9 \\
- \\
2.512,6 \\
- \\
- \\
- \\
- \\
- \\
- \\
- \\
- \\
- \\
-\end{array}$ \\
\hline
\end{tabular}


Rev. IG, São Paulo, 2(2):17-33, jun./dez. 1981

Tab. If - Cont.

LOCAL: PLANALTO (Fda. Luchesi)

\begin{tabular}{|c|c|c|c|c|c|c|c|}
\hline \multirow{2}{*}{$\begin{array}{c}\text { AMOSTRA } \\
\text { (Prof.) } \\
\text { m }\end{array}$} & \multirow{2}{*}{$\begin{array}{c}\text { AREIA } \\
\%\end{array}$} & \multirow{2}{*}{$\begin{array}{c}\text { SILTE + } \\
\text { ARGILA \% }\end{array}$} & \multirow{2}{*}{$\begin{array}{c}\mathrm{CaCO}_{3} \\
\%\end{array}$} & \multicolumn{2}{|c|}{ POROSIDADE } & \multicolumn{2}{|c|}{$\begin{array}{l}\text { PERMEABILIDADE } \\
\text { K(m.D. })\end{array}$} \\
\hline & & & & $\%$ & $=$ & $\perp$ & S.O. \\
\hline 20 & 86,25 & 13,75 & 3,98 & 14,40 & - & - & 45,4 \\
\hline 22 & 88,37 & 11,63 & 3,85 & 26,34 & & & \\
\hline 23 & 81,57 & 18,43 & & 24,40 & 153,9 & 49,4 & - \\
\hline 24 & 80,25 & 19,75 & 7,13 & $\begin{array}{l}24,49 \\
26,82\end{array}$ & & & \\
\hline 27 & 80,25 & 19,75 & 3,73 & & - & - & 0,0 \\
\hline 28 & 84,05 & 15,95 & 10,27 & 7,13 & - & & \\
\hline 29 & 80,25 & 19,75 & 5,82 & 13,45 & - & - & 79,4 \\
\hline 30 & 94,92 & 5,08 & & & 16,8 & 0,0 & - \\
\hline 32 & 97,25 & 2,75 & 2,49 & 32,39 & $1.422,3$ & 948,2 & - \\
\hline 33 & 91,13 & 8,87 & & & 948,2 & 948,2 & - \\
\hline 34 & 92,13 & 7,87 & 6,16 & 22,29 & 514,0 & 322,0 & - \\
\hline 35 & 88,87 & 11,13 & 5,82 & 29,77 & 0,0 & - & - \\
\hline 36 & 99,55 & 4,45 & & & 239,7 & 56,1 & - \\
\hline 37 & 82,23 & 17,77 & & & - & - & 86,6 \\
\hline 38 & 93,00 & 7,00 & 8,31 & 27,22 & 395,8 & 125,9 & - \\
\hline 40 & 78,38 & 21,62 & 6,70 & 26,64 & 17,8 & 11,1 & - \\
\hline 41 & 94,75 & 5,25 & & & 158,0 & 113,7 & - \\
\hline 42 & 83,47 & 16,53 & 14,06 & 20,82 & 12,6 & 0,0 & - \\
\hline $\begin{array}{l}43 \\
46\end{array}$ & 82,67 & 17,33 & 12,24 & 18,36 & 0,0 & - & - \\
\hline 48 & & & $\begin{array}{l}13,52 \\
17,61\end{array}$ & 7,89 & - & - & 0,0 \\
\hline 50 & & & 12,25 & 4,91 & - & - & 0,0 \\
\hline 52 & & & 10,38 & & & & \\
\hline 54 & & & 12,44 & 4,14 & - & - & 0,0 \\
\hline 56 & & & 15,60 & 3,00 & - & - & 0,0 \\
\hline 58 & & & 17,64 & 7,14 & - & - & 0,0 \\
\hline 60 & & & 17,70 & 11,92 & - & - & 0,0 \\
\hline $\begin{array}{l}61 \\
65\end{array}$ & & & $\begin{array}{r}7,80 \\
12,70\end{array}$ & 5,26 & - & - & 0,0 \\
\hline 67 & & & 2,31 & 1,93 & - & - & $\begin{array}{l}0,0 \\
0,0\end{array}$ \\
\hline 69 & & & 5,27 & 8,62 & - & - & 0,0 \\
\hline 70 & 75,00 & 25,00 & 4,17 & 7,31 & - & - & 0,0 \\
\hline $\begin{array}{l}72 \\
74\end{array}$ & & & $\begin{array}{l}13,08 \\
14,75\end{array}$ & & - & - & \\
\hline 76 & 79,62 & 20,37 & $\begin{array}{r}14,75 \\
8,45\end{array}$ & 11,63 & - & - & 0,0 \\
\hline 77 & 75,45 & 24,55 & 7,77 & & - & - & 18,7 \\
\hline 80 & 94,37 & 5,63 & 15,85 & 17,38 & - & - & 406,3 \\
\hline 82 & 83,37 & 16,63 & 2,32 & 24,11 & - & - & 5,0 \\
\hline 85 & 93,12 & 6,88 & 2,49 & 19,88 & - & - & 125,5 \\
\hline 87 & 72,90 & 27,10 & 2,38 & 11,03 & - & - & 73,5 \\
\hline 88 & 92,25 & 7,75 & & & 395,8 & 277,1 & - \\
\hline 88,5 & 90,07 & 9,93 & & & 122,5 & 40,2 & - \\
\hline 89 & 86,50 & 13,50 & & & 91,7 & 50,7 & - \\
\hline 90 & 66,25 & 33,75 & 0,00 & 6,34 & - & - & 23,9 \\
\hline 91 & 75,80 & 24,20 & & & 0,0 & - & - \\
\hline 92 & 79,75 & 20,25 & 0,32 & 11,09 & - & - & 0,0 \\
\hline 93 & 77,22 & 22,78 & 7,32 & 8,37 & - & - & 36,5 \\
\hline
\end{tabular}


Rev. IG, São Paulo, 2(2):17-33, jun./dez. 1981

Tab.1g- Cont.

LOCAL: MARIA BENTA - SÃO JOSÉ DO RIO PRETO

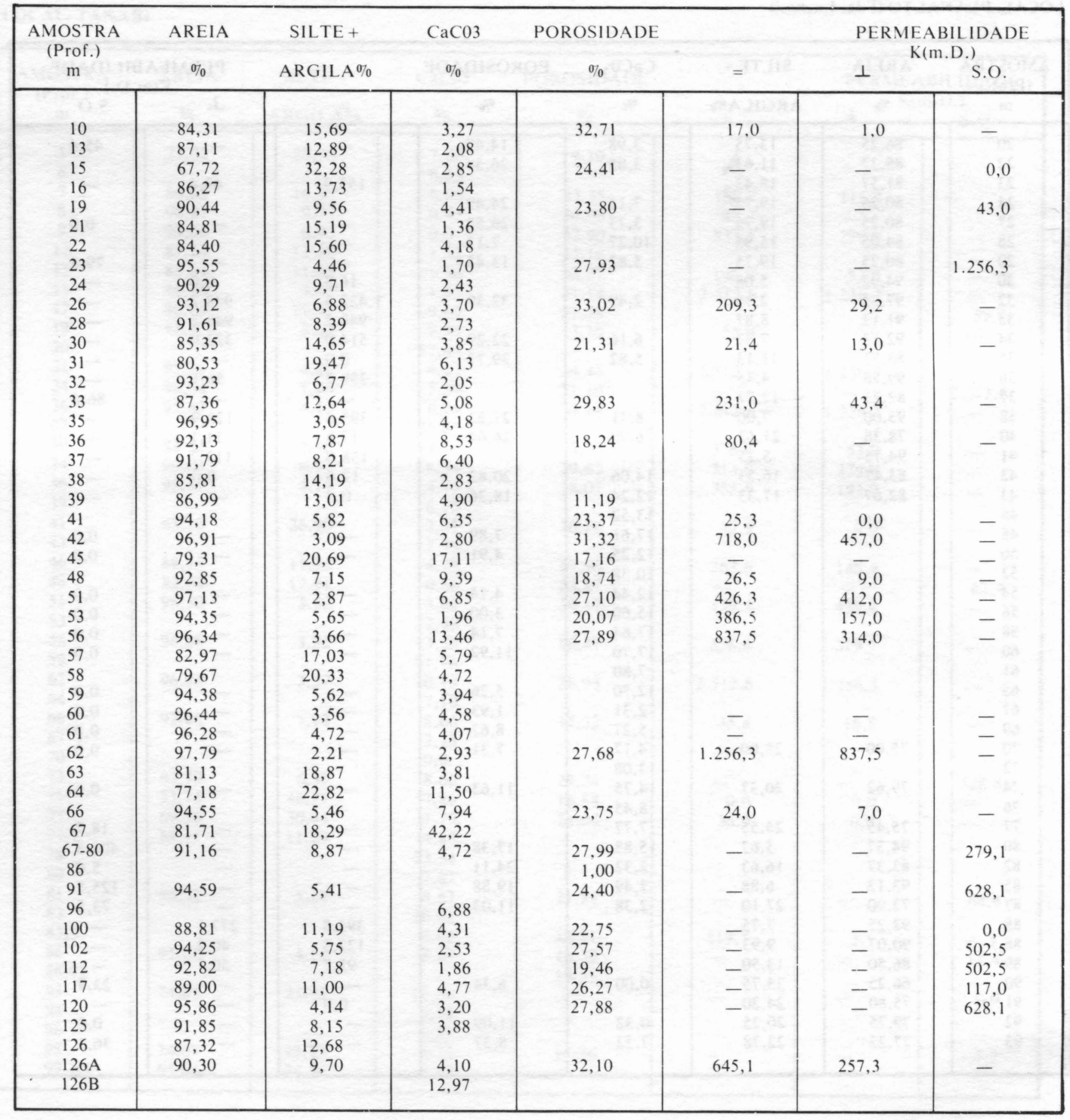


Rev. IG, São Paulo, 2(2):17-33, jun./dez. 1981

Tab. 1h - Cont.

LOCAL: PEVÁPOLIS

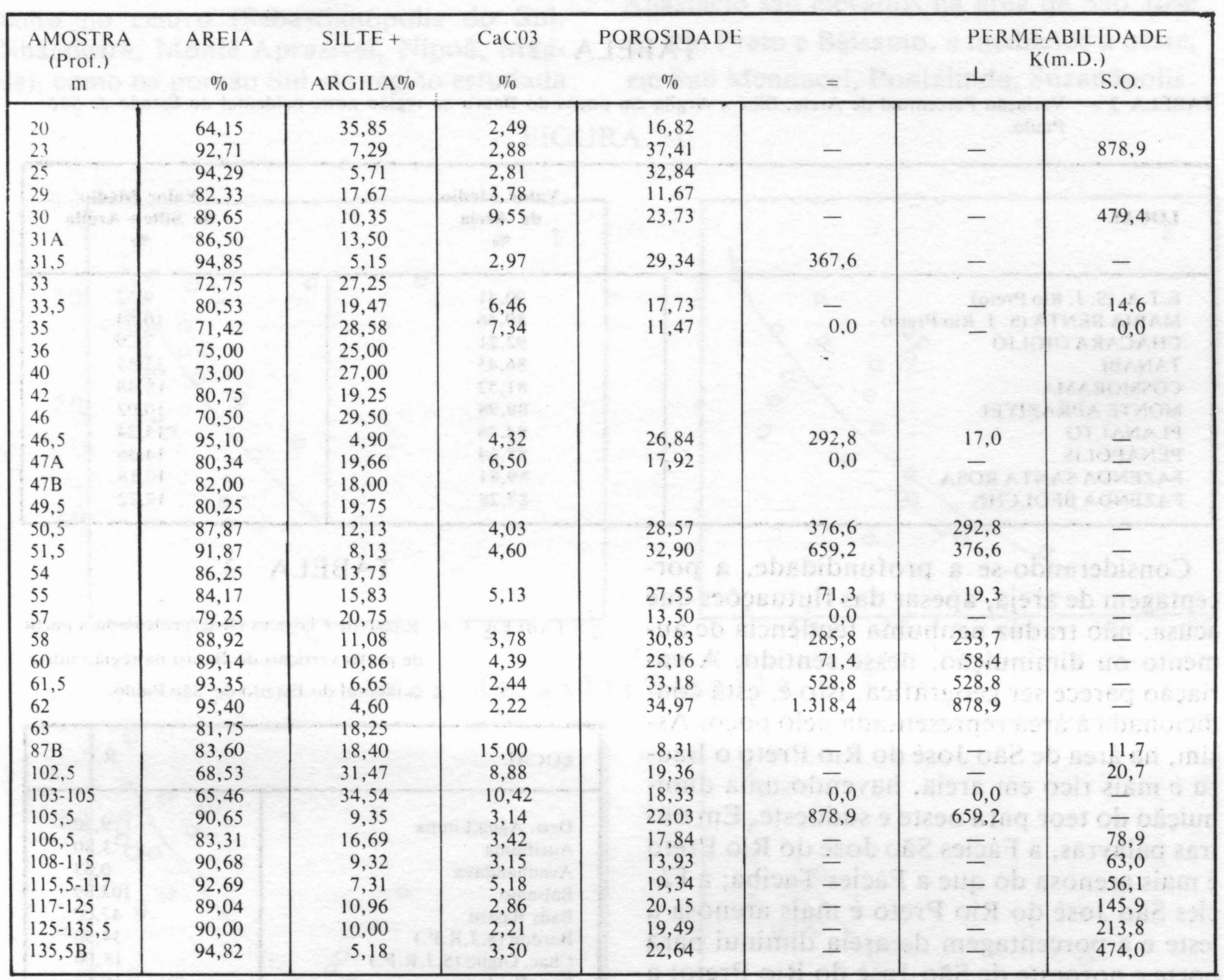

Tab. 1i - Cont.

LOCAL: SUD MENNUCCI (Fazenda Sta. Rosa)

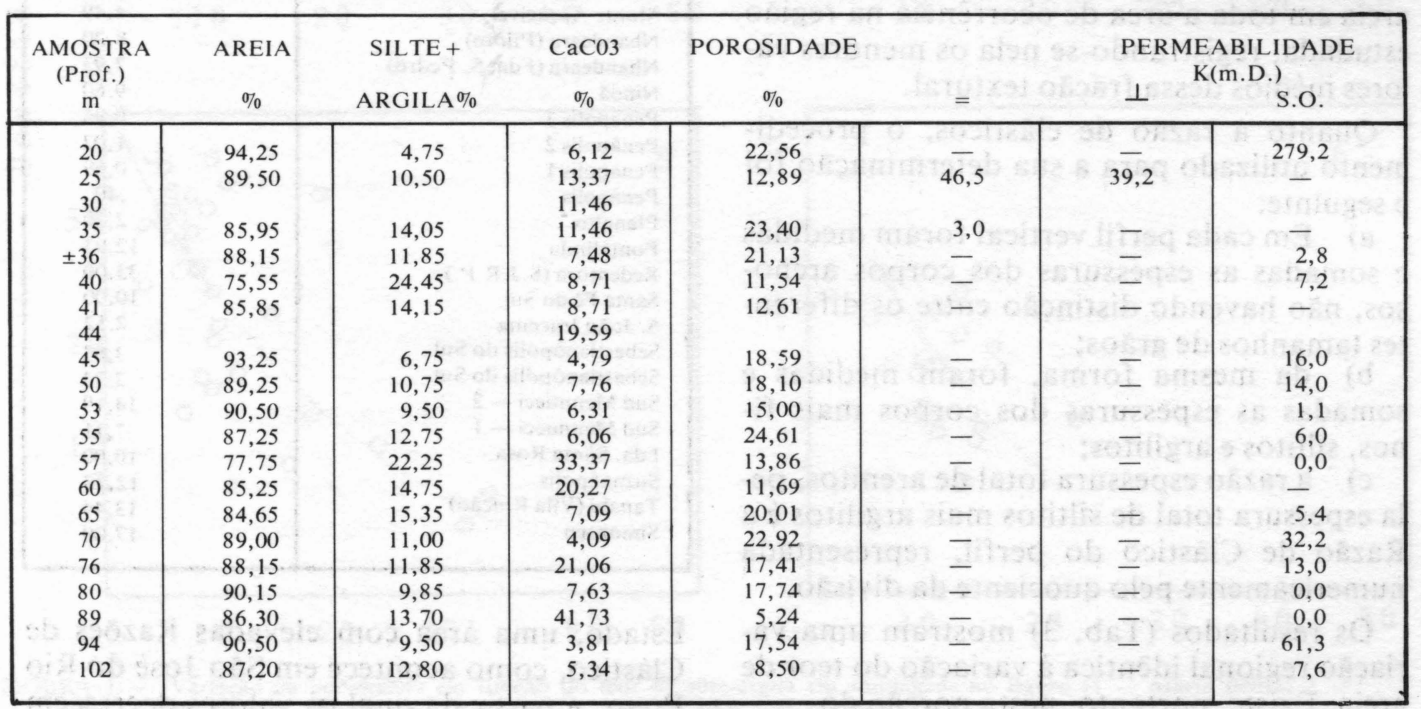


TEXTURA E RAZÃO DE CLÁSTICOS

Em todas as amostras de arenito, analisadas texturalmente, ocorre sempre predomi- nância da fração areia sobre as frações silte e argila. A areia representa sempre mais de $80 \%$ em todos os perfis (Tab.2).

TABELA 2

TABELA 2 - Variação Percentual de Areia, Silte e Argila em poços do Bauru na região norte-ocidental do Estado de São Paulo.

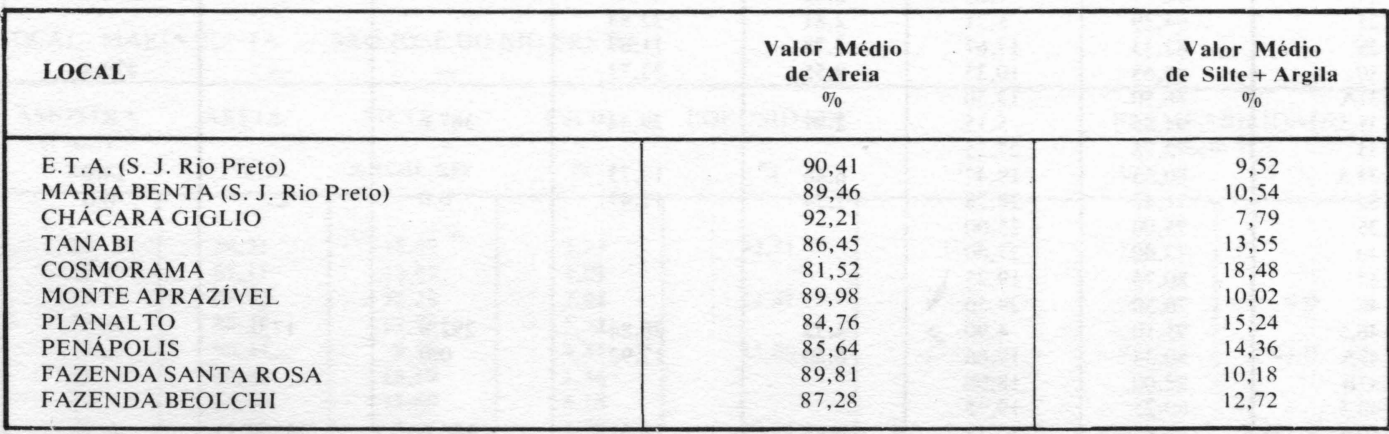

Considerando-se a profundidade, a porcentagem de areia, apesar das flutuações que acusa, não traduz nenhuma tendência de aumento ou diminuição, nesse sentido. A variação parece ser geográfica, isto é, está condicionada à área representada pelo poço. Assim, na área de São José do Rio Preto o Bauru é mais rico em areia, havendo uma diminuição do teor para oeste e sudoeste. Em outras palavras, a Fácies São José do Rio Preto é mais arenosa do que a Fácies Taciba; a Fácies São José do Rio Preto é mais arenosa a leste e a porcentagem de areia diminui para norte e noroeste de São José do Rio Preto; a Formação Santo Anastácio é muito mais arenosa na região de São José do Rio Preto do que a oeste, na área de Santa Fé do Sul, Sud Mennucci e Pereira Barreto; a Fácies Taciba parece ter a mesma porcentagem de areia em toda a área de ocorrência na região estudada, registrando-se nela os menores valores médios dessa fração textural.

Quanto à razão de clásticos, o procedimento utilizado para a sua determinação foi o seguinte:

a) Em cada perfil vertical foram medidas e somadas as espessuras dos corpos arenosos, não havendo distinção entre os diferentes tamanhos de grãos;

b) da mesma forma, foram medidas e somadas as espessuras dos corpos mais finos, siltitos e argilitos;

c) a razão espessura total de arenitos, pela espessura total de siltitos mais argilitos é a Razão de Clástico do perfil, representada numericamente pelo quociente da divisão.

Os resultados (Tab. 3) mostram uma variação regional idêntica à variação do teor de areia. Existe, portanto, nesta porção do

\section{TABELA 3}

TABELA 3 - Razão de Clásticos (R.C.) calculada a partir de perfis verticais do Bauru na região norteocidental do Estado de São Paulo.

\begin{tabular}{|l|c|}
\hline LOCAL & R.C. \\
\hline & \\
\hline Dest. Água Limpa & 9,70 \\
Auriflama & 3,80 \\
Avanhandava & 0,63 \\
Bálsamo & 102,09 \\
Bady Bassitt & 47,00 \\
Bordon (S.J.R.P.) & 34,50 \\
Chac. Giglio (S.J.R.P.) & 18,00 \\
Eng. Balduino & 19,67 \\
E.T.A. (S.J.R.P.) & 42,00 \\
I.P.A. (S.J.R.P.) & 54,60 \\
Maceno (S.J.R.P.) & 34,50 \\
Magda - 1 & 5,92 \\
Magda - 2 & 6,85 \\
Maria Benta (S.J.R.P.) & 30,50 \\
Meridiano & 10,00 \\
Monte Aprazivel & 4,49 \\
Nhandeara (Piloto) & 8,20 \\
Nhandeara (Fda. S. Pedro) & 7,93 \\
Nipoã & 9,60 \\
Penápolis 3 & 0,96 \\
Penápolis 2 & 1,02 \\
Penápolis 1 & 0,69 \\
Penápolis & 440 \\
Planalto & 2,70 \\
Pontalinda & 12,93 \\
Redentora (S.J.R.P.) & 33,00 \\
Santa Fé do Sul & 10,00 \\
S. João Iracema & 2.52 \\
Sebastianópolis do Sul & 3,63 \\
Sebastianópolis do Sul & 2,73 \\
Sud Mennucci - 2 & 14,19 \\
Sud Mennucci - 1 & 7,11 \\
Fda. Santa Rosa & 10,00 \\
Suzanápolis & 12,28 \\
Tanabi (Vila Rincão) & 13,44 \\
Simonsen & 17,00 \\
\hline
\end{tabular}

Estado, uma área com elevadas Razões de Clástico, como acontece em São José do Rio Preto, a partir da qual os valores decrescem 
para noroeste, na Fácies São José do Rio Preto (Tanabi, Simonsen, Meridiano). A Fácies Taciba, apresenta valores baixíssimos tanto no centro (Sebastianópolis do Sul, Nhandeara, Monte Aprazível, Nipoã, Magda), como na porção Sul da região estudada
(Planalto, Penápolis e Avanhandava). Os valores apresentados pela Formação Santo Anastácio são elevados na área de São José do Rio Preto e Bálsamo, e medianos a oeste, em Sud Mennucci, Pontalinda, Suzanápolis.

FIGURA 1
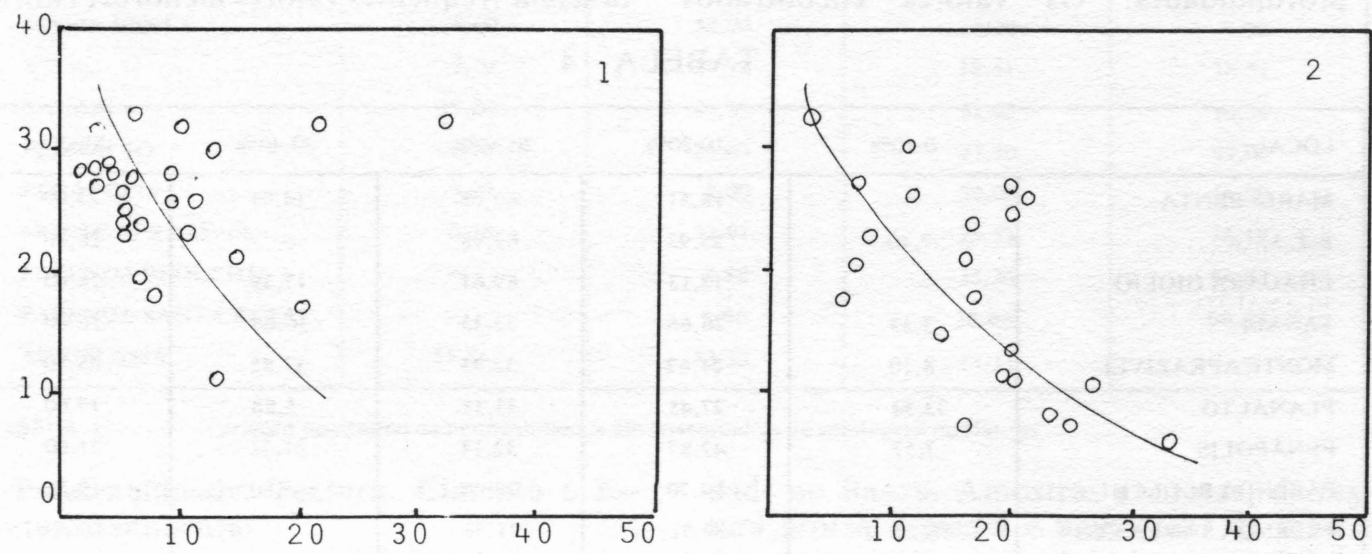

Teor de silte-argila - \%
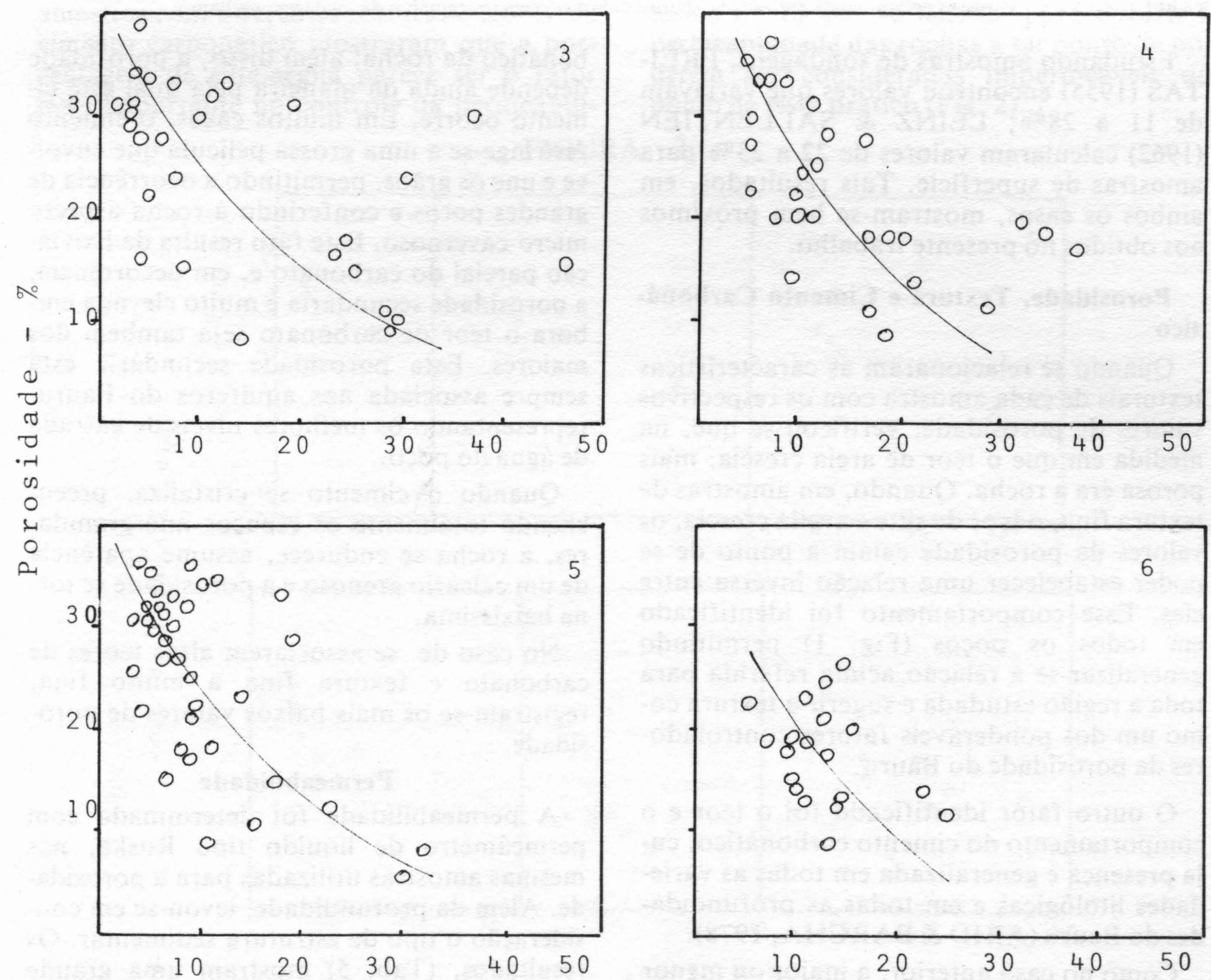

FIGURA 1 - Variação da porosidade em função do teor de silte-argila em sondagens no Bauru (1 - Maria Benta; 2 Planalto; 3 - Tanabi; 4 - Penápolis; 5 - Monte Aprazivel; 6 - Fazenda Santa Rosa). 


\section{Porosidade}

A determinação dos valores da porosidade efetiva foi feita em porosímetro modelo Rus$\mathrm{ka}$, utilizando-se o método de injeção de mercúrio na amostra sob pressão. Foram efetuadas mais de 350 medidas em amostras selecionadas e representativas de diferentes profundidades. Os valores encontrados
(Tab. 1) são extremamente variáveis de um poço a outro e no mesmo poço, não havendo qualquer tendência de variação relacionada à profundidade. Comparada com a classificação de CHILINGAR et. alii (1972), a porosidade do Bauru, na grande maioria das amostras, varia de porosidade de muito alta a porosidade alta $(>25 \%$ a $15-25 \%)$, embora sejam freqüentes valores menores (Tab. 4).

TABELA 4

\begin{tabular}{|c|c|c|c|c|c|}
\hline LOCAL & $0-10 \%$ & $10-20 \%$ & $20-30 \%$ & $30-40 \%$ & Média \\
\hline MARIA BENTA & - & 18,51 & 66,68 & 14,81 & 25,00 \\
\hline E.T.A. & 7,40 & 25,92 & 62,98 & - & 26,00 \\
\hline CHÁCARA GIGLIO & & 13,13 & 69,61 & 17,39 & 26,00 \\
\hline TANABI & 3,33 & 26,66 & 33,33 & 36,68 & 26,00 \\
\hline MONTE APRAZIVEL & 8,10 & 21,62 & 32,43 & 37,85 & 25,50 \\
\hline PLANALTO & 33,34 & 27,45 & 33,33 & 5,88 & 17,00 \\
\hline PENÁPOLIS & 3,57 & 42,87 & 32,14 & 21,42 & 21,00 \\
\hline FAZENDA BEOLCHI & - & 64,70 & 29,40 & 5,90 & 19,55 \\
\hline FAZENDA SANTA ROSA & 10,20 & 57,91 & 31,57 & - & 16,60 \\
\hline AURIFLAMA & - & 22,22 & 22,22 & 55,56 & 26,30 \\
\hline
\end{tabular}

TABELA 4 - Variação percentual da porosidade e porosidade média em testemunhos de sondagens no Bauru.

Estudando amostras de sondagens, FREITAS (1955) encontrou valores que variavam de 11 a $28 \%$; LEINZ \& SALLENTIEN (1962) calcularam valores de 22 a $23 \%$ para amostras de superfície. Tais resultados, em ambos os casos, mostram-se bem próximos aos obtidos no presente trabalho.

\section{Porosidade, Textura e Cimento Carboná- tico}

Quando se relacionaram as características texturais de cada amostra com os respectivos valores de porosidade, verificou-se que, na medida em que o teor de areia crescia, mais porosa era a rocha. Quando, em amostras de textura fina, o teor de silte e argila crescia, os valores da porosidade caíam a ponto de se poder estabelecer uma relação inversa entre eles. Esse comportamento foi identificado em todos os poços (Fig. 1) permitindo generalizar-se a relação acima referida para toda a região estudada e sugerir a textura como um dos ponderáveis fatores controladores da porosidade do Bauru.

$\mathrm{O}$ outro fator identificado foi o teor e o comportamento do cimento carbonático, cuja presença é generalizada em todas as variedades litológicas e em todas as profundidades do Bauru (ARID \& BARCHA, 1978).

Como no caso anterior, a maior ou menor porosidade pode estar também relacionada a um grande ou pequeno teor de cimento car- bonático da rocha; além disso, a porosidade depende ainda da maneira pela qual este cimento ocorre. Em muitos casos, o cimento restringe-se a uma grossa película que envolve e une os grãos, permitindo a ocorrência de grandes poros e conferindo à rocha aspecto micro-cavernoso. Este fato resulta da lixiviação parcial do carbonato e, em decorrência, a porosidade secundária é muito elevada embora o teor de carbonato seja também dos maiores. Esta porosidade secundária está sempre associada aos aquíferos do Bauru, representando os melhores níveis de entrada de água do poço.

Quando o cimento se cristaliza, preenchendo totalmente os espaços intergranulares, a rocha se endurece, assume aparência de um calcário arenoso e a porosidade se torna baixíssima.

No caso de se associarem altos teores de carbonato e textura fina a muito fina, registram-se os mais baixos valores de porosidade.

\section{Permeabilidade}

A permeabilidade foi determinada com permeâmetro de líquido tipo Ruska, nas mesmas amostras utilizadas para a porosidade. Além da profundidade, levou-se em consideração o tipo de estrutura sedimentar. Os resultados, (Tab. 5) mostram uma grande variação de valores, desde permeabilidade muito alta a permeabilidade muito baixa, se- 
gundo a classificação de CHILINGAR et alii (1972). A maior parte das amostras traduz, entretanto, permeabilidade alta (1.000 a 100 milidarcies),

PERMEABILIDADE (em m.D.)

TABELA 5

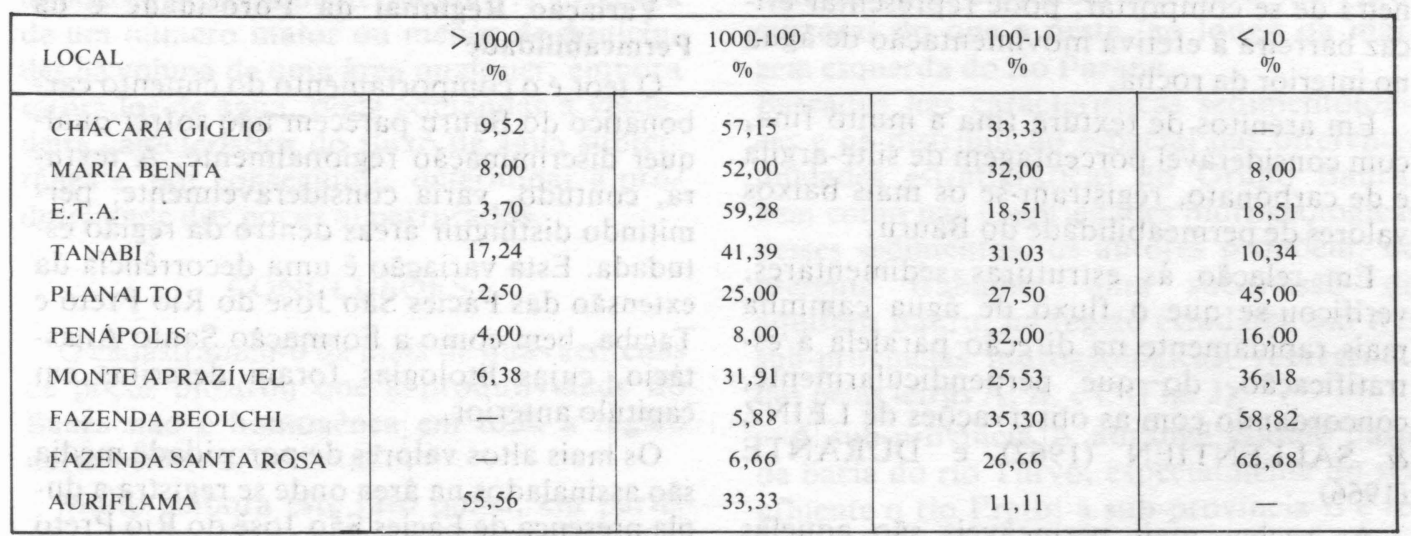

TABELA 5 - Variação percentual da permeabilidade em testemunhos de sondagens no Bauru.

Permeabilidade, Textura, Cimento e Estrutura Sedimentar

Os ensaios de laboratório realizados em amostras com diferentes texturas e teores de cimento carbonático mostraram que a porcentagem de silte-argila parece ser o fator mais importante no controle da permeabili- dade do Bauru. Amostras arenosas, de textura grossa a média e baixo teor de matriz possuem, via de regra, elevada permeabilidade. Em geral, porcentagens de silte-argila acima de 10 são suficientes para reduzir a permeabilidade das rochas a tal ponto de poderem ser consideradas impermeáveis do ponto de vista prático (Fig. 2).

FIGURA 2

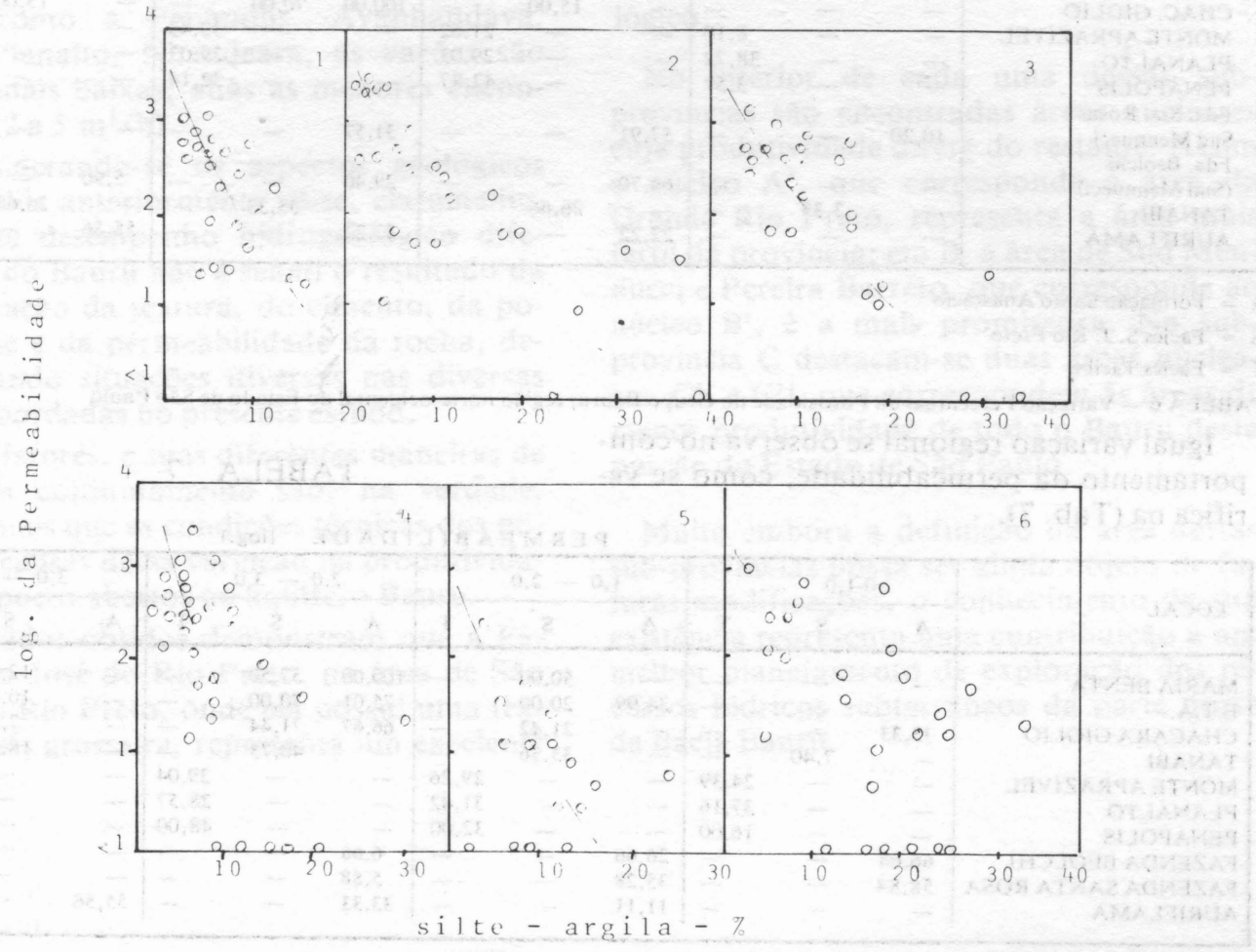

FIGURA 2 -

Variação da Permeabilidade (em log.) em função do teor de silte-argila, em amostras de sondagens no Bauru (1 Maria Benta; 2 - Tanabi; 3 - Penápolis; 4 - Monte Aprazível; 5 - Fazenda Santa Rosa; 6 - Planalto). 
O outro fator, o cimento carbonático, exerce também um certo controle sobre a permeabilidade de tal forma que em concentrações acima de $10 \%$ e dependendo da maneira de se comportar, pode representar eficaz barreira à efetiva movimentação de água no interior da rocha.

Em arenitos de textura fina a muito fina, com considerável porcentagem de silte-argila e de carbonato, registram-se os mais baixos valores de permeabilidade do Bauru.

Em relação às estruturas sedimentares, verificou-se que o fluxo de água caminha mais rapidamente na direção paralela à estratificação, do que perpendicularmente, concordando com as observações de LEINZ \& SALLENTIEN (1962) e DURANTE (1966).

As rochas mais permeáveis são aquelas com laminação cruzada planar, de textura marcadamente arenosa, de granulação média. Os menores valores são encontrados em arenitos maciços, de granulação muito fina e alto teor de matriz. Amostras maciças porém de textura grosseira a média e pouco teor de matriz são, também, muito permeáveis.

\section{Variação Regional da Porosidade e da Permeabilidade}

O teor e o comportamento do cimento carbonático do Bauru parecem não sofrer qualquer discriminação regionalmente. A textura, contudo, varia consideravelmente, permitindo distinguir áreas dentro da região estudada. Esta variação é uma decorrência da extensão das Fácies São José do Rio Preto e Taciba, bem como a Formação Santo Anastácio, cujas litologias foram descritas em capítulo anterior.

Os mais altos valores de porosidade média são assinalados na área onde se registra a dupla presença de Fácies São José do Rio Preto e da Formação Santo Anastácio. Os mais baixos, estão associados à Fácies Taciba e aos sedimentos de borda da Formação Santo Anastácio (Tab. 6).

TABELA 6

\begin{tabular}{|c|c|c|c|c|c|c|c|c|c|c|c|c|}
\hline \multirow{2}{*}{ LOCAL } & \multicolumn{3}{|c|}{$0-10 \%$} & \multicolumn{3}{|c|}{$10-20 \%$} & \multicolumn{3}{|c|}{$20-30 \%$} & \multicolumn{3}{|c|}{$30-40 \%$} \\
\hline & A & $\mathrm{S}$ & $\mathrm{T}$ & A & $\mathrm{S}$ & $\mathrm{T}$ & A & $\mathrm{S}$ & $\mathrm{T}$ & A & $\mathrm{S}$ & $\mathrm{T}$ \\
\hline MARIA BENTA & - & - & - & - & 21,00 & - & 87,50 & 63,22 & - & 12,50 & 15,78 & - \\
\hline E. T. A. & - & 20,00 & - & 16,66 & 26,67 & - & 83,34 & 53,33 & - & - & - & - \\
\hline CHAC. GIGLIO & - & - & - & - & 15,00 & - & 100,00 & 70,00 & - & - & 15,00 & - \\
\hline MONTE APRAZIVELL & - & - & 8,10 & - & - & 21,62 & - & - & 32,43 & - & - & 37,85 \\
\hline PLANALTTO & - & - & 38,72 & - & - & 29,03 & - & - & 29,03 & - & - & 3,22 \\
\hline PENÁPÓLIS & - & - & 3,57 & - & - & 42,87 & - & - & 32,14 & - & - & 21,42 \\
\hline Fda. Sta. Rosa- & & & & & & & & & & & & \\
\hline $\begin{array}{l}\text { Sud Mennucci } \\
\text { Fda. Beolchi }\end{array}$ & 10,20 & - & - & 57,91 & - & - & 31,57 & - & - & - & - & - \\
\hline (Sud Mennucci) & - & - & - & 64,70 & - & - & 29,40 & - & - & 5,90 & - & - \\
\hline TANABI & - & 3,33 & - & - & 26,66 & - & - & 33,33 & - & - & 36,68 & - \\
\hline AURIFLAMA & - & - & - & 22,22 & - & - & 22,22 & - & - & 55,56 & - & - \\
\hline
\end{tabular}

$\mathrm{A}=$ Formação Santo Anastácio

$\mathrm{S}=$ Fácies S. J. Rio Preto

$T=$ Fácies Taciba

TABELA 6 - Variação Percentual da Porosidade no Grupo Bauru, região norte-ocidental do Estado de São Paulo

Igual variação regional se observa no comportamento da permeabilidade, como se verifica na (Tab. 7).

TABELA 7

PER ME A B I L I D A D E (log.)

\begin{tabular}{|c|c|c|c|c|c|c|c|c|c|c|c|c|}
\hline \multirow{2}{*}{ LOCAL } & \multicolumn{3}{|c|}{$>0-1,0$} & \multicolumn{3}{|c|}{$1,0-2,0$} & \multicolumn{3}{|c|}{$2,0-3,0$} & \multicolumn{3}{|c|}{$3,0-3,5$} \\
\hline & A & $\mathrm{S}$ & $\mathrm{T}$ & A & $\mathrm{S}$ & $\mathrm{T}$ & A & $\mathrm{S}$ & $\mathrm{T}$ & A & $\mathrm{S}$ & \\
\hline MARIA BENTA & - & - & - & - & 50,00 & - & 100,00 & 37,50 & - & - & 12,50 & - \\
\hline E.T.A. & - & - & - & 24,99 & 20,00 & - & 75,01 & 70,00 & - & - & 10,00 & - \\
\hline CHÁCARA GIGLIO & 33,33 & - & - & - & 21,42 & - & 66,67 & 71,44 & - & - & 7,14 & - \\
\hline TANABI & - & 7,40 & - & - & 33,36 & - & - & 40,73 & - & - & 18,51 & - \\
\hline MONTE APRAZÍVEL & - & - & 24,39 & - & - & 29,26 & - & - & 39,04 & - & - & 7,31 \\
\hline PLANALTO & - & - & 37,16 & - & - & 31,42 & - & - & 28,57 & - & - & 2,85 \\
\hline PENÁPOLIS & - & - & 16,00 & - & - & 32,00 & - & - & 48,00 & - & - & 4,00 \\
\hline FAZENDA BEOLCHI & 66,68 & - & - & 26,66 & - & - & 6,66 & - & - & - & - & - \\
\hline FAZENDA SANTA ROSA & 58,84 & - & - & 35,28 & - & - & 5,88 & - & - & - & - & - \\
\hline AURIFLAMA & - & - & - & 11,11 & - & - & 33,33 & - & - & 55,56 & - & - \\
\hline
\end{tabular}

Fm. Santo Anastácio

$\mathrm{T}=$ Fácies Taciba

TABELA 7 - Variação Percentual da Permeabilidade no Grupo Bauru, região norte-ocidental do Estado de São Paulo 
Isto explica a aptidão de certas áreas, dentro da região estudada, de armazenar e transportar água com valores de transmissividade maiores do que em outras, onde essa aptidão é relativamente menor. A presença de um número maior ou menor de aquicludes na coluna de uma área qualquer, embora saturados de água, pode comandar a verdadeira característica do fluxo de água subterrânea e, por conseguinte, determinar a produtividade dos poços aí perfurados.

\section{CONCLUSÕES}

O cadastramento de mais de duas centenas de poços mostrou que a produtividade do Bauru não é homogênea em toda a região norte-ocidental do Estado.

Muito embora este fato possa, em parte, ser atribuído às próprias características técnicas de tais poços, construídos sob os mais diferentes critérios, existe, no entanto, um outro fator, de natureza geológica, muito mais amplo, capaz de interferir decisivamente no comportamento hidrogeológico do Bauru na região.

Em áreas, como a de São José do Rio Preto, têm-se verificado vazões excepcionais, em se tratando de poços no Bauru, da ordem de até $100 \mathrm{~m}^{3} / \mathrm{h}$, e com valores médios ótimos, de 20 a $30 \mathrm{~m}^{3} / \mathrm{h}$. Por outro lado, áreas como a Penápolis, Avanhandava, Lins, Planalto, Nhandeara, as vazões são muito mais baixas, aliás as menores encontradas $\left(2\right.$ a $\left.5 \mathrm{~m}^{3} / \mathrm{h}\right)$.

Considerando-se os aspectos geológicos abordados anteriormente vê-se, claramente, que este desempenho hidrogeológico diferencial do Bauru não é senão o resultado da combinação da textura, do cimento, da porosidade e da permeabilidade da rocha, determinando situações diversas nas diversas áreas abordadas no presente estudo.

Tais fatores, e suas diferentes maneiras de atuarem conjuntamente são, na verdade, muito mais que as condições técnicas dos poços, as causas dessa variação na produtividade dos poços abertos no aquífero Bauru.

Os dados obtidos demonstram que a Fácies São José do Rio Preto, na área de São José do Rio Preto, onde ela possui uma textura mais grosseira, representa um excelente reservatório de água subterrânea, com caracteríticas bem superiores às da Fácies Taciba. Da mesma maneira as características hidrogeológicas da Formação Santo Anastácio, a leste da região estudada, são muito mais promissoras do que a oeste, ao longo da margem esquerda do rio Paraná.

Baseados nas características sedimentológicas e na distribuição espacial das diferentes unidades estratigráficas do Grupo Bauru, bem como nas propriedades hidrogeológicas desses sedimentos, os autores propõem, no presente trabalho, uma subdivisão do aquífero Bauru, na região estudada, em três sub-províncias hidrogeológicas, representadas pelas letras A, B, e C (Fig. 3).

A sub-província A abrange grande parte da bacia do rio Turvo, especialmente do seu afluente o rio Preto; a sub-província B é representada pelo espigão divisor do São José dos Dourados e rio Grande, pela região marginal do rio Paraná, desde Santa Fé do Sul, alargando-se, para sul, englobando as áreas de Auriflama, Sud Mennucci e Pereira Barreto; finalmente, a sub-província $\mathrm{C}$, compreende todo o Alto e Médio São José dos Dourados, continuando-se para sul até as reas de Araçatuba, Penápolis e Lins. Comparadas entre si, a sub-província A é mais produtiva, seguida de B. A sub-província C é a que possui o menor desempenho hidrogeológico.

No interior de cada uma dessas subprovíncias são encontradas áreas nucleares cuja produtividade difere do restante. Assim o núcleo A', que corresponde à área da Grande Rio Preto, representa a área mais fertil da província; em B, a área de Sud Mennucci e Pereira Barreto, que corresponde ao núcleo $\mathrm{B}$ ', é a mais promissora. $\mathrm{Na}$ subprovíncia $C$ destacam-se duas áreas nucleares, C', e C', que correspondem às áreas de menor produtividade de todo o Bauru desta porção do Estado de São Paulo.

Muito embora a definição da área destas sub-províncias possa ser ainda objeto de futuras modificações, o conhecimento de sua existência representa uma contribuição a um melhor planejamento de exploração dos recursos hídricos subterrâneos da parte norte da Bacia Bauru. 


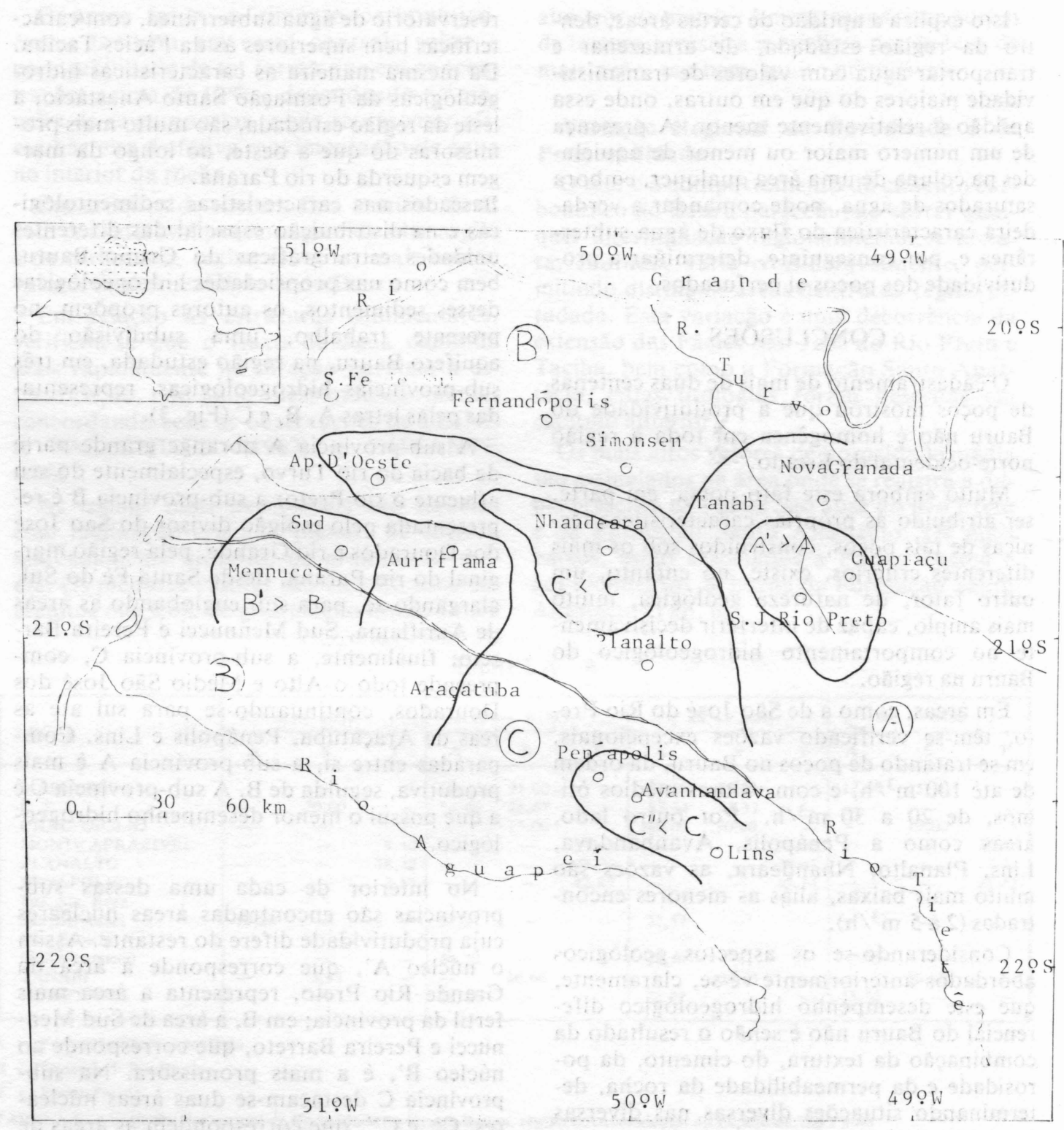

FIGURA 3 - Sub-Províncias hidrogeológicas do Grupo Bauru, região norte-ocidental do Estado de São Paulo. 


\section{BIBLIOGRAFIA}

ARID, F.M. - 1967 - A Formação Bauru na região norte-ocidental do Estado de São Paulo. São José do Rio Preto, Faculdade de Filosofia, Ciências e Letras. 126 p. (Geociências, 1).

$$
\text { ; BARCHA, S.F. - } 1978 \text { - Comporta- }
$$

mento do cimento carbonático na seqüência vertical da Formação Bauru, região norte-ocidental do Estado de São Paulo. Naturalia: Rev. de Ciênc., São José do Rio Preto, 4:7-16.

BARCHA, S.F.; ARID, F.M. - 1977 - Parâmetros granulométricos de estruturas sedimentares e interpretação do ambiente dinâmico da Formação Bauru (Ks). Naturalia: Rev. de Ciênc., São José do Rio Preto, 3:15-34.

$$
\text { - } 1980 \text { - Aspectos geológicos e provin- }
$$
ciais hidrogeológicos da Formação Bauru na região norte-ocidental do Estado de São Paulo. São José do Rio Preto, UNESP, Instituto de Biociências, Letras e Ciências Exatas. /Tese Livredocência/.

$$
\text { - } 1980^{\mathrm{a}} \text { - Estratigrafia do Bauru, na }
$$
região norte-ocidental do Estado de São Paulo. São Paulo, Sociedade Brasileira de Geologia. (prelo)

CHILINGAR, G.V. et alii. - 1972 - Porosity and permeability. In: FAIRBRIDGE, R.W. Encyclopedia of geochemistry and environmental sciences. S.L.p., sd. v.4A p. 964-970.

DURANTE, A. - 1966 - Estudos de permeabilidade de arenitos em laboratório, com emprego de Permeâmetro. São Paulo, Instituto Geográfico e Geológico. $42 \mathrm{p}$.
FREITAS, R.O. - 1955 - Sedimentação estratigráfica e tectônica da série Bauru, Estado de São Paulo. São Paulo, Universidade, FFCL. 179p. (Boletim, 194 - Geologia, 14)

$$
\text { - } 1964 \text { - Grupo Bauru. In: SÃO PAU- }
$$
LO. INSTITUTO GEOGRÁFICO E GEOLÓGICO. Geologia do Estado de São Paulo. São Paulo. p.126-164. (Boletim, 41).

LEINZ, V:; SALLENTIEN, B. - 1962 - Água subterrânea no Estado de São Paulo e regiões limitrofes. Bol. Soc. Bras. Geol., São Paulo, 11(1):27-36.

MEZZALIRA, S. - 1974 - Contribuição ao conhecimento da estratigrafia e paleontologia do Arenito Bauru. São Paulo, Instituto Geográfico e Geológico. 162p. (Boletim, 51).

SOARES, P.C. et alii. - 1979 - Ensaio de caracterização estratigráfica do cretáceo no Estado de São Paulo: Grupo Bauru. In: SIMPÓSIO REGIONAL DE GEOLOGIA, 2. ${ }^{\circ}$, Rio Claro. Resumos. São Paulo, Sociedade Brasileira de Geologia. p.30-31.

$$
\text { - } 1980 \text { - }
$$

Rev, Bras. Geoc., São Paulo, 10(3):177-185.

SUGUIO, K. et alii. - 1977 - Comportamentos estratigráficos e estrutural da Formação Bauru nas regiões administrativas 7 Bauru, 8 São José do Rio Preto e 9 Araçatuba no Estado de São Paulo. In: SIMPÓSIO REGIONAL DE GEOLOGIA, 1. São Paulo. Atas. São Paulo, Sociedade Brasileira de Geologia. p.231-247. 